\title{
How human activities in commercial areas contribute to phthalate ester pollution in street dust of Taiwan
}

\author{
Lee Sung-Tse ${ }^{1}$, Lin Chitsan ${ }^{2,{ }^{*}}$, Vu Chi Thanh ${ }^{3,{ }^{*}}$, Chen Yi-Cyuan ${ }^{2}$, Chen Kang-Shin ${ }^{1}$, \\ Villanueva Ching-Maria ${ }^{4}$
}

${ }^{1}$ National Sun Yat-Sen University, Institute of Environmental Engineering, Kaohsiung 80424, Taiwan
2 National Kaohsiung University of Science and Technology, Department of Marine Environmental
Engineering, Kaohsiung 81157 , Taiwan
${ }^{3}$ The University of Alabama in Huntsville, Civil and Environmental Engineering Department, Huntsville,
AL 35899, USA
${ }^{4}$ IFREMER, Laboratoire Biologies Halieutiques, STH, Z.I. Pointe du Diable BP 70, Plouzané, France
${ }^{*}$ Corresponding authors : Lin Chitsan, email address : $\underline{\text { ctlin@webmail.nkmu.edu.tw ; Vu Chi Thanh, }}$
email address : tv0009@uah.edu

\section{Abstract :}

Exposure to phthalate esters (PAEs) poses health risks to humans. Much research has been performed evaluating PAE levels in foodstuffs, river sediment and drinking water, but little attention has been paid to their presence in urban outdoor environments where human activities are highly intense. Here we evaluated PAE presence and distribution in street dust in Kaohsiung, the most industrialized city in Taiwan. Our results showed that PAEs were ubiquitous in fifty-two street-dust samples (levels of total PAEs 5.4-989.2 mg kg-1). Di-(2-ethylhexyl) phthalate was the most abundant congener observed and made up $85.0 \%, 79.7 \%$, and $97.2 \%$ of the total PAEs found in industrial, residential and commercial areas, respectively. PAE levels in street dust in commercial areas (night markets) were significantly higher, suggesting a higher risk of contamination on people present in these areas (H value $>\mathrm{XU} 2$ ). In residential and commercial areas, the higher the intensity of human activity, the higher the PAE content observed. PAE content decreased progressively from the center to the outskirts of the Houjing night market, suggesting that the increased human and consumer activities inside this commercial hotspot were the main PAE source in street dust. Children had higher estimated daily intakes (DIs) than adults and dermal absorption contributed more to these levels than oral ingestion. Although all calculated Dls were below referenced danger thresholds, street dust PAEs in the area should remain an environmental concern especially since night markets play an important role in Taiwanese/Asian culture and economy. Contrary to other studies, PAEs in this study were found less related to industrial manufacturing activities but highly linked to commercial activities. These findings are relevant for future pollution prevention efforts dedicated to mitigating public exposure to PAEs. 
Main findings

PAE levels in street dust are related to commercial activities. Night markets, an important commercial activity in Taiwan, were found to contribute considerably to PAE contamination in street dust.

\section{Graphical abstract}
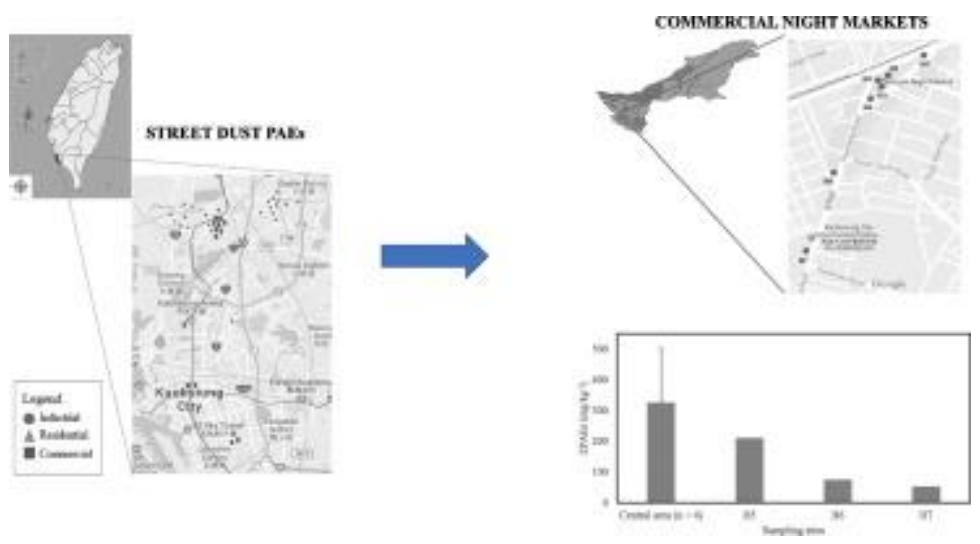

\section{Highlights}

PAE levels in street dust are related to commercial activities. PAEs were detected in all samples in the range of 5.4-989.2 $\mathrm{mg} \cdot \mathrm{kg}^{-1}$. Estimated PAEs non-dietary DIs are higher in children than those in adults. Night markets contributed considerably to street dust PAE contamination.

Keywords : Phthalate esters (PAEs), Street dust, Night markets, Consumer exposure, Daily intakes, Commercial areas 


\section{Introduction}

Phthalate esters (PAEs), flexible and elastic chemicals, are used widely as plasticizers, particularly in products made of polyvinyl chloride (PVC) (Niu et al. 2014). They are found in a wide variety of daily products including children's toys, pesticides, food packaging, household furnishings, personal care products, medicines and even foodstuffs (Niu et al. 2014, Skrbic et al. 2016). One hundred fifty million tons of plastic is manufactured globally every year and PAEs are consumed at a rate of 6.0 to 8.0 million tons annually (Niu et al. 2014). As a result, PAEs are widespread in soil, water, sediments and air (Zeng et al. 2008b).

PAEs are classified as endocrine disruptors that pose health risks to both terrestrial and aquatic species (Zeng et al. 2008a, Niu et al. 2014). Exposure to these substances leads to various adverse health complications (Kozumbo et al. 1982, Kluwe 1986). Six specific PAEs (dimethyl phthalate (DMP), diethyl phthalate (DEP), di-n-butyl phthalate (DnBP), benzyl butyl phthalate (BBP), di(2-ethylhexyl) phthalate (DEHP), di-n-octyl phthalate (DnOP) are highly toxic and are categorized as priority contaminants by the US Environmental Protection Agency (USEPA 2013) and the European Union (EU) (Zeng et al. 2008b, Wu et al. 2012). Therefore, PAE contamination and propagation are often the subject of worldwide monitoring studies (Niu et al. 2014, Skrbic et al. 2016).

Kaohsiung city is the most industrialized area in Taiwan. It has a population of around three million and is an important economic and industrial center in Asia. In Kaohsiung, PAEs have been found in river sediment (Lin et al. 2009), drinking water (Yang et al. 2014), soil (Kaewlaoyoong et al. 2018) and foodstuff (Wu et al. 2013). PAEs were also detected in human urine in studies performed following a scandal involving industries that used PAEs as a substitute of emulsifier to food products they manufactured (Chen et al. 2016). Since that time, PAE contamination and associated health risk have been a major concern of Kaohsiung City government and its citizens (Yang et al. 2014).

A large number of studies have investigated PAEs in indoor dust (Bornehag et al. 2005, Hwang et al. 2008, Orecchio et al. 2013, Zhang et al. 2013, Ait Bamai et al. 2014, Jeon et al. 2016, Albar et al. 2017, Larsson et al. 2017, Subedi et al. 2017), and human incidences of PAEs from indoor contamination have been reported (Pei et al. 2013, Tran et al. 2016, Albar et al. 
2017). However, while indoor contamination can be controlled or managed by inhabitants, PAE street dust exposure is less easily controlled (Lan et al. 2012, Skrbic et al. 2016). Although street dust PAE levels can serve as an important indicator of contamination, their presence in outdoor matrices is not usually monitored and is, therefore, not well documented (Zhang et al. 2013, Skrbic et al. 2016). To date, only a few studies of street dust PAE contamination have been reported, in China and Serbia (Lan et al. 2012, Zhang et al. 2013, Skrbic et al. 2016) and no studies have measured PAE contamination in street dust of Taiwan. Here, the industrialization has led to the rapid development of areas where plastic and metal processing industries thrive for the last forty years. The most industrialized city in Taiwan is Kaohsiung City, home to giant metal-plating and plastic industrial plants (Vu et al. 2017a, Vu et al. 2017b, Lee et al. 2018).

Like many other Asian countries, Taiwan has many night markets. There are around three hundred night markets operating in multiple cities throughout Taiwan and they are considered a signature of the Taiwanese/Asian culture (Sun et al. 2012, Chen et al. 2014). Night markets exist in almost every area of Kaohsiung City, and there are thousands of people working in or visiting these night markets every day (Zhao et al. 2011, Chen et al. 2014, Liao 2017). Levels of PAEs in street dust in these night market areas, therefore, deserve to be studied because they could pose serious concerns on human health and wellbeing.

As mentioned above, investigations in outdoor dust are very scarce, as well as studies showing any link between these PAE contamination occurrences and the intensity of outdoor human activities. Therefore, this study aims to analyze the occurrence of PAEs in samples collected in Kaohsiung city to determine zones of high PAE contaminations in street dust. Daily intakes from the level of exposure to PAEs in street dust in both adults and children through ingestion and dermal pathways were estimated and pollution prevention strategies suggested.

\section{Materials and methods}

\subsection{Study location and sample collection sites}

Kaohsiung city, situated in southern Taiwan, is one of the most rapidly growing industrial cities in Asia (Chia-Hong 2013). We collected a total of 52 street dust samples from three industrial, three residential and five commercial areas in the city from November 2014 to May 
2015. The samples were collected on sunny days between 9 am and $4 \mathrm{pm}$. There was no precipitation at any of the sites two weeks before the sampling. Most street dust samples were taken within one week. Daily variations of street dust PAEs during a week of sampling was considered outside the scope of this study and were assumed to be negligible. Sampling sites selected were areas potentially contaminated by industrial, residential and commercial activities. Three industrial parks and three residential sites were located in Kaohsiung's crowded Dashe, Renwu and Nanzih districts. The commercial sites were located at the crowded Houjing night market (Figure 1). Here, the daily commercial use of plastics despite multiple government regulations for their control may contribute to elevated occurrence of organic contamination (Caliendo 2015, Liao 2017, Lin et al. 2017b). To the best of our knowledge, this study is the first to investigate organic contamination caused by plastics used and collected from this typical popular and traditional commercial area in Asia. A detailed description of the sampling sites and the samples collected is provided in Table S1.

Sample collection and analysis basically followed the method described in Skrbic et al. (2016). Street dust was collected using a portable small-sized vacuum cleaner (8 BLACK + DECKER CHV1410L Cordless Dust-Buster Hand Vacuum). At each site, five sub-samples (within $50 \times 50 \mathrm{~m}$ ) were merged to form a composite sample (Skrbic et al. 2016). At least one duplicate sample was collected for each study area. Samples were kept in aluminum bags under cool conditions in a temperature-controlled box during the transportation to the laboratory. During the sampling and sample analysis, precautions were taken to avoid further PAE contamination in the laboratory (Lin et al. 2009). Samples were homogenously mixed and filtered through a stainless-steel sieve (60 mesh) and then stored at $-20{ }^{\circ} \mathrm{C}$ until extraction.

\subsection{Sample extraction and instrumental analysis}

A PAE standard mixture containing dimethyl phthalate (DMP), diethyl phthalate (DEP), di-n-butyl phthalate (DnBP), benzyl butyl phthalate (BBP), di(2-ethylhexyl) phthalate (DEHP) and di-n-octyl phthalate (DnOP) was purchased from AccuStandard, Inc., New Haven, CT. The concentration of each PAE in the mixture was $1000 \mu \mathrm{g} \mathrm{L}^{-1}$. Benzyl benzoate was used as an internal standard (99 \% purity; Sigma Aldrich, USA) (Lan et al. 2012, Skrbic et al. 2016). All 
other reagents and chemicals were of analytical grade and purchased from SUPELCO Analytical, Bellefonte, PA, USA.

Solvent extraction and sample analysis methods were previously described in Zhang et al. (2013). After adding a known quantity of the internal standard, $10 \mathrm{~g}$ sample was mixed in a conical flask containing $30 \mathrm{~mL}$ dichloromethane for $15 \mathrm{~min}$. This process was repeated three times. The supernatants were combined and concentrated to $2 \mathrm{~mL}$ in a Turbo Vap (Biotage, USA) and finally to $0.5 \mathrm{~mL}$ using gentle nitrogen flow $(5 \mathrm{psi})$. The final extracts $(0.5 \mathrm{~mL})$ were analyzed using an Agilent 6890-5973 gas chromatography-mass selective detector (GC-MSD) equipped with HP-5MS capillary column (30 m x $0.25 \mathrm{~mm}$ x $0.5 \mu \mathrm{m}$ ) (injection volume $1 \mu \mathrm{L}$, helium flow rate $1 \mathrm{~mL} \cdot \mathrm{min}^{-1}$ ). Temperature was initially set at $45^{\circ} \mathrm{C}$ for 1 minute before increasing to $310^{\circ} \mathrm{C}$ at the rate of $10{ }^{\circ} \mathrm{C} \cdot \mathrm{min}^{-1}$ for seven minutes. Selective ion monitoring (SIM) mode was used to measure the PAE content based on the retention time and identify characteristic ions. Calibration curves for all the measured compounds were constructed with eight levels $\left(1.25,2.5,5,10,20,40,80\right.$ and $\left.100 \mu \mathrm{g} \cdot \mathrm{mL}^{-1}\right)$. All calculations of concentrations and calibrations were carried out based on the built standard calibration curves (average relative standard deviation of response factors $<20 \%, \mathrm{R}^{2}>0.995$ ). Detection limits (DLs; values in $\mathrm{mg}$ $\mathrm{kg}^{-1}$ ) were established using the standard deviation of triplicate findings from the analysis of seven samples with the same concentrations (Lin et al. 2017b). DLs (values in $\mathrm{mg} \mathrm{kg}^{-1}$ ) for each PAE compound were as follows: 0.2 (DEHP), 0.2 (DnBP), 0.1 (DnOP), 0.2 (BBP), 0.1 (DEP) and 0.1 (DMP). Each batch of ten samples included a laboratory and a procedural blank, a standard mid-point check, a duplicate, a spiked and a matrix-spiked duplicate sample. Procedural (field) blanks were analyzed to investigate the possible contamination from sampling (vacuum cleaner, collection bags or manipulation). All blanks showed below ND (not detected) values. Standard mid-point recoveries ranged from $92 \%$ to $108 \%$. The relative percent difference (RPD) of the duplicates were lower than 10\%. Spiked and matrix-spiked duplicate recoveries ranged from $80 \%$ to $118 \%$, which were within acceptable values. Details of daily checking before the operation of the GC-MS system can be found in Lin et al. (2017a).

To minimize potential contamination during the PAE analysis, the laboratory glassware we used was free of plastics and pre-treated with continuous heating and rinsing as previously 
described by Skrbic et al. (2016). Furthermore, samples were prepared as quickly as possible to reduce preparation time (less than 48 hours). High-purity dichloromethane (DCM) was used.

\subsection{Estimation of exposure}

Daily intake (DI ) values through ingestion and dermal pathways were calculated according to USEPA (2013) in order to assess all possible routes of human exposure to PAEs in street dust. In this study, we used the approach of Skrbic et al. (2016) to estimate the exposure from PAEs in street dust. Specifically, the DIs of each pathway were calculated as follows:

- DI $_{\text {ingest }}=\frac{\mathrm{C}_{\mathrm{s}} \times \mathrm{IR} \times \mathrm{EF} \times \mathrm{ED} \times \mathrm{CF}}{\mathrm{BW} \times \mathrm{TA}}$

where $C_{s}$ is the PAE concentration present in street dust samples $\left(\mathrm{mg} \mathrm{kg}^{-1}\right)$, IR the ingestion rate $\left(\mathrm{mg}^{-d_{a y}}{ }^{-1}\right), \mathrm{EF}$ the exposure frequency (days year ${ }^{-1}$ ), ED exposure duration (years), $\mathrm{CF}$ conversion factor $\left(\mathrm{kg} \cdot \mathrm{mg}^{-1}\right), \mathrm{BW}$ average body weight $(\mathrm{kg})$ and TA average exposure in time (days).

- $\mathrm{DI}_{\text {dermal }}=\frac{\mathrm{C}_{\mathrm{s}} \times \mathrm{SA} \times \mathrm{AF} \times \mathrm{ABS} \times \mathrm{EF} \times \mathrm{ED} \times \mathrm{CF}}{\mathrm{BW} \times \mathrm{TA}}$

where SA is the skin surface area $\left(\mathrm{cm}^{2} \cdot \mathrm{day}^{-1}\right)$, AF the skin adherence factor $\left(\mathrm{mg} . \mathrm{cm}^{-2}\right)$, and ABS the fraction of dermally absorbed contaminant (dimensionless).

The parameters used for the estimation of exposure were taken from USEPA (2013) and listed in Table $\mathrm{S} 2$.

\subsection{Statistical analysis}

The non-parametric Kruskal Wallis test was used to determine the difference in PAE contents between different sampling sites and city areas. The difference between the PAE congeners in different areas, i.e., districts and night markets of Kaohsiung City was also examined. Not detected values were replaced by DL values in the calculations. The values of $H$ statistic were compared with the critical values of chi-square $\left(\chi_{U}^{2}\right)$ and an $\alpha=0.05$ was considered significant. Statistical operations were performed using IBM SPSS statistics for Windows, Version 22. 


\section{Results and discussion}

\subsection{PAE levels in street dust collected from industrial, residential and commercial areas}

To identify the main area source of PAEs in street dust, we analyzed samples collected in three main zones of the city. Table 1 shows the PAE contamination levels in street dust in Kaohsiung's industrial, residential and commercial areas. Of the PAE congeners, DEHP was the most abundant and made up the largest percentage of total PAE levels in all areas: industrial (85\%), residential (79.7\%) and commercial (97.2\%). Total concentrations of DEHP ranged from six to seven hundred times that of the second and third most abundant PAE congeners, D $n \mathrm{BP}$ and $\mathrm{D} n \mathrm{OP}$, which constituted $9.2 \%$ and $4.6 \%$ of levels of total PAEs in the industrial areas, $13.7 \%$ and $4.5 \%$ in residential areas, and $1.4 \%$ and $1.2 \%$ in commercial areas, respectively. These findings are consistent with those of Skrbic et al. (2016) and Lan et al. (2012) based on their street dust analyses and Zhang et al. (2013) on pollution analysis from outdoor settled dust.

We found no differences between PAE contents in industrial and residential areas $(\mathrm{H}$ value $<\chi_{\mathrm{U}}^{2}$ ). Commercial areas, on the other hand, had higher PAE contents compared to either the industrial or residential areas (both $\mathrm{H}$ values $>\chi_{\mathrm{U}}^{2}$ ). This was an unexpected result since PAE contamination is often attributed to industrial rather than commercial activities (Wu et al. 2015). Surprisingly high concentrations (range $101-553 \mathrm{mg} \mathrm{kg}^{-1}$ ) of PAEs were found in a street dust sample collected in the vicinity of Houjing night market, where commercial activity is intense (discussed later).

Most PAE contamination studies focused on soil, sediment, or indoor dust (Zeng et al. 2008b, Lin et al. 2009, Skrbic et al. 2016) but neglect street dust, which is also an important contamination indicator as humans, especially in large cities, are at risk of direct and indirect exposure to street dust contamination (Skrbic et al. 2016). To date, there have only been a few studies published on PAE level analysis in street dust. Lan et al. (2012) analyzed sixteen PAEs $\left(121-3223 \mathrm{mg} \mathrm{kg}^{-1}\right)$ in thirty indoor and fifteen outdoor dust samples in Guangzhou (China) and found PAE content in indoor dust to be higher than in outdoor dust. This was also the conclusion made by Zhang et al. (2013) in their study of six PAEs in 215 indoor $\left(188 \pm 0.005 \mathrm{mg} \mathrm{kg}^{-1}\right)$ and 145 outdoor $\left(25.5 \pm 0.004 \mathrm{mg} \mathrm{kg}^{-1}\right)$ samples of settled dust in Nanjing (China). Skrbic et al. 
(2016) studied six PAEs in street dust in Serbia and found that samples collected from the parks of Novi Sad contained higher PAE content $\left(5.45 \mathrm{mg} \mathrm{kg}^{-1}\right)$ than those collected from industrial and residential areas. In our study, PAEs in street dust ranged from 5.4 to $989.2 \mathrm{mg} \mathrm{kg}^{-1}$ with elevated PAE values associated with increasing commercial activity.

Comparing our findings with the handful of PAE studies of street dust (Table 2), we found the level of PAE contamination in Kaohsiung City to be higher than those reported in other studies (Lan et al. 2012, Zhang et al. 2013, Skrbic et al. 2016). Generally, PAE levels reported in Nanjing (Zhang et al. 2013) and Novi Sad (Skrbic et al. 2016) are low compared to those reported in Guangzhou (Lan et al. 2012) and this study. The highest DMP and DEP levels found in Kaohsiung City's street dust ( 0.8 and $0.5 \mathrm{mg} \mathrm{kg}^{-1}$, respectively) were considerably higher than those observed in Guangzhou (0.122 and $0.117 \mathrm{mg} \mathrm{kg}^{-1}$, respectively) (Lan et al. 2012) and in Novi Sad (0.021 and $0.017 \mathrm{mg} \mathrm{kg}^{-1}$, respectively) (Skrbic et al. 2016). The highest DnBP and BBP levels observed in our study (29.1 and $2.1 \mathrm{mg} \mathrm{kg}^{-1}$, respectively) were lower than the values reported by Lan et al. (2012) (59.5 and $10.7 \mathrm{mg} \mathrm{kg}^{-1}$, respectively) but were one to two orders higher than those reported by Skrbic et al. (2016) (0.213 and $0.351 \mathrm{mg} \mathrm{kg}^{-1}$, respectively). The highest DEHP and DnOP levels in this study (955.6 and $17.7 \mathrm{mg} \mathrm{kg}^{-1}$ ) were also higher than those reported by Lan et al. (2012) (779 and $3.73 \mathrm{mg} \mathrm{kg}^{-1}$ ) and Skrbic et al. (2016) (4.82 and $0.035 \mathrm{mg} \mathrm{kg}^{-1}$ ). The differences in outdoor PAE levels and fingerprints reported in Taiwan, China and Serbia indicate differences in intensity and sources contributing to various PAEs, thus cultural and geographical dependent pollution prevention strategies are warranted.

\subsection{Street dust PAE levels classified by the intensity of human activities}

Human activities are suspected as being the main source of PAEs in street as well as indoor dust (Kang et al. 2012, Zheng et al. 2015, Iwegbue and Obi 2016). Therefore, we attempted to classify the intensity of PAE contamination as a function of human activity collected per sampling site. Three intensity levels of human activity groups (low, medium, high) were allotted for each area. A detailed description of the criteria used to assess the intensity of human activities on streets in the mix of commercial-residential areas and the results of the assessment for each sampling site are provided in Table S3 and Table S4, respectively. Because this study is the first to characterize the effects of human activity intensities on PAEs in street 
dust, the criteria set in Table S3 were based upon our experience and observation that PAE contamination in street dust may be caused mainly by automobile and motorcycle tires, slippers, and plastic bags and materials used for food and merchandise storage and packaging. Our results (Table 3) show that there were differences in PAE concentrations between the three human activity intensity groups $\left(\mathrm{H}\right.$ values $>\chi_{\mathrm{U}}^{2}$ ), suggesting that human activities were the main cause of PAEs in street dust. Levels of total PAEs in high intensity areas were estimated at $122.4 \pm$ $100.3 \mathrm{mg} \mathrm{kg}^{-1}$ while levels observed in medium and low intensity areas were $46.3 \pm 24.1$ and $20.9 \pm 6.2 \mathrm{mg} \mathrm{kg}^{-1}$, respectively. Similarly, the concentrations of the most abundant PAE congener, DEHP, were significantly higher in the high intensity area $\left(106.6 \pm 94.0 \mathrm{mg} \mathrm{kg}^{-1}\right)$ than those observed in the medium intensity areas $\left(31.7 \pm 21.9 \mathrm{mg} \mathrm{kg}^{-1}\right)\left(\mathrm{H}\right.$ value $\left.>\chi_{\mathrm{U}}^{2}\right)$. We also observed DEHP concentrations in high intensity areas to be elevated compared to those in low intensity zones $\left(10.1 \pm 2.9 \mathrm{mg} \mathrm{kg}^{-1}\right)\left(\mathrm{H}\right.$ value $\left.>\chi_{\mathrm{U}}^{2}\right)$. For the other congeners, similar trends were also observed despite slight variations between the three categories.

Based on our observations, a strong link exists between human activity intensity and PAE levels in the commercial-residential areas (Table 3). Elevated PAE contamination seems to be correlated to an increase in number of transportation activities due to the presence of commercial activities in these sub-zones. Among the PAE contaminants, DEHP and DnBP were observed in street dust collected in all stations. DEHP was the highest $\left(30.7-363.3 \mathrm{mg} \mathrm{kg}^{-1}\right)$ in the most intensified anthropogenic activity zones while $\mathrm{D} n \mathrm{BP}$ was the highest in areas with moderate human movement. Aside from the presence of commercial activities, phthalates contamination in residential areas may be caused by other unexpected sources such as street vendors' sandals, foot wear and plastic containers for storage and packaging (Rane 2011). To date and to the best of our knowledge, no study has ever reported the strong relationship between human activities and PAEs in street dust. Therefore, this study may be used as a reference for future pollution prevention plans as these should take into account the intensity of human activities and consumer behaviors to regulate PAE contamination from street dust.

\subsection{Spatial characterization of PAEs in the Houjing night market and vicinity}

Of the three zones considered, the commercial Houjing area had the highest amount of PAE contamination in street dust. We collected some samples in different areas of the Houjing 
night market (Figure 2). Since street dust usually represents recent accumulation of dust particles, samples in the Houjing night market were collected over a single day (May $4^{\text {th }}$ ). Four samples $(\mathrm{H} 1, \mathrm{H} 2, \mathrm{H} 3$ and H4) were collected in the center of the night market where intensive human activities were likely to occur the most. Three other samples were taken at different distances from the central area. H5 was located around 100 m north while H6 and H7 were located at 300 $\mathrm{m}$ and $500 \mathrm{~m}$ south of the central area of the night market. As can be seen Figure 3, PAE concentrations in the central area were significantly higher $\left(325.9 \pm 175.3 \mathrm{mg} \mathrm{kg}^{-1}\right)$ than other stations $\left(\mathrm{H}\right.$ value $\left.>\chi_{\mathrm{U}}^{2}\right)$. Contaminant concentration values observed declined the further the sample area was located from the center. About $209.5 \mathrm{mg} \mathrm{kg}^{-1}$ was observed at H5. Considerably lower values were recorded at $\mathrm{H} 6$ and $\mathrm{H} 7$ (74.3 and $52.1 \mathrm{mg} \mathrm{kg}^{-1}$, respectively) $\left(\mathrm{H}\right.$ values $\left.>\chi_{\mathrm{U}}^{2}\right)$. These results suggest that the market center is a "hot zone" where elevated PAE contamination seems to occur. The decreasing trend from the center is due to the decline of DEHP concentrations, gradually dropping from the central area $\left(313.9 \pm 161.1 \mathrm{mg} \mathrm{kg}^{-1}\right)$ to $\mathrm{H} 5$ (206.4 $\left.\mathrm{mg} \mathrm{kg}^{-1}\right)$, H6 (71.2 $\left.\mathrm{mg} \mathrm{kg}^{-1}\right)$ and $\mathrm{H} 7\left(13.9 \mathrm{mg} \mathrm{kg}^{-1}\right)$. Similar results were also observed for DnBP (from $5.7 \pm 9.1$ to $0.6 \mathrm{mg} \mathrm{kg}^{-1}$ ), DMP (from $0.3 \pm 0.3 \mathrm{mg} \mathrm{kg}^{-1}$ to ND value) and BBP (from $0.4 \pm$ $0.8 \mathrm{mg} \mathrm{kg}^{-1}$ to ND value). Although the only one sample collected for $\mathrm{H} 5, \mathrm{H} 6$ and $\mathrm{H} 7 \mathrm{might}$ affect the representativeness of the sampling, the results again showed a strong correlation between human commercial activities and PAE street dust contamination. This clearly indicates that commercial activities and consumer behaviors contribute to PAEs in street dust and further studies may be pursued to implement a sound pollution prevention plan as a primary goal.

Night markets provide thousands of jobs and attract millions of visitors every year (Sun et al. 2012, Liao 2017). Common activities in the night markets include trade and consumption of local foods and sales of other merchandise such as clothes, footwear, house utensils, toys, etc. (Kavlock et al. 2002, Sun et al. 2012). The highest source of PAE contamination is the use of plastics for packaging and transport of goods (Liao 2017). Furthermore, there have been reports of plasticizers being used as food and drink thickeners to increase their market value (Rudel et al. 2011). Since night markets are often the most crowded and busiest areas day and night in Taiwan, the risk of PAE contamination is high and persistent, posing a considerably negative impact on human health (Zhao et al. 2011, Chen et al. 2014).

\subsection{Human exposure to PAEs in street dust}


In this study, daily intakes (DIs) were estimated to assess public exposure to PAEs in street dust. This approach of estimating exposure to organic contamination in dust has been used widely (Lan et al. 2012, Zhang et al. 2013, Skrbic et al. 2016). Exposure to PAEs can occur through multiple pathways such as intake of food (Wu et al. 2013) and ingestion of drinking water (Yang et al. 2014), inhalation of indoor/outdoor air (Pei et al. 2013) and/or penetration through skin (Guo et al. 2014). Compared to indoor dust, PAE levels of outdoor dust should be much lower since outdoor environment is wider and less concentrated than indoor environment (Zhang et al. 2013). However, while sources of PAEs in indoor environment can be easily controlled/managed (e.g. simply by replacing the current PAE-containing materials by non PAEcontaining materials), those leaking PAEs in outdoor environment are much more difficult to control. Night markets are considered the signature of Asian cultures and they attract millions of visitors from all over the world every year. Sources of PAEs in crowded night markets are various, complex and thus very difficult to control. This study found widespread distribution of high concentrations of PAEs in street dust in crowded commercial night markets, which therefore makes exposure to street dust PAEs seemingly unavoidable. Exposure to PAEs in street dust thus can contribute considerably to overall PAE exposure.

Table 4 compares the DIs of PAEs in adults and children through ingestion and dermal pathways. We selected ingestion and dermal pathways taking the same approach of DI calculation for indoor/outdoor dust used by similar studies (Zhang et al. 2013, Skrbic et al. 2016). Among the PAEs, ingested and dermal DEHP contamination were the highest in both adults and children. Children, however, were found to be more susceptible to exposure via ingestion than adults. The risk is dangerously higher for younger children or toddlers who are likely to put plastic spoons and food covering in their mouths or chew on them. For most of the PAE contaminants, we found significantly higher DI values due to dermal contact and ingestion in children compared to adults, respectively $\left(\mathrm{H}\right.$ values $\left.>\chi_{\mathrm{U}}^{2}\right)$. For adults, dermal contact contributed more to PAE exposure than oral ingestion. Dermal contact may be due to constant contact with plastic bags used for packaging (Sun et al. 2012, Caliendo 2015, Liao 2017) or other phthalatecontaminated materials (Chen et al. 2014) as well as larger skin surface areas exposed to contaminated clothes or personal care products (Kavlock et al. 2002, Guo et al. 2014).

The resulting DI values in this study were compared with the two most popular standard 
values--reference dose (RfD) and tolerable daily intake (TDI) (Zhang et al. 2013). USEPA announced RfDs for DEP, DnBP, and DEHP to be 800, 100 and $20 \mu \mathrm{g} \cdot \mathrm{kg}^{-1}{ }_{\text {bw }} \mathrm{day}^{-1}$, respectively. Similarly, the European Food Safety announced the TDIs for DnBP and DEHP to be 10 and 50 $\mu \mathrm{g} . \mathrm{kg}^{-1}{ }_{\mathrm{bw}} \mathrm{day}^{-1}$, respectively. The DIs observed in this study did not exceed these regulatory values, indicating that PAEs in street dust alone would not likely pose high risks to human health. However, unlike other studies in which extensive PAE analyses were made (Niu et al. 2014, Zhang et al. 2015), we only tested for a small number of PAE congeners in the city's street dust. Therefore, the exposure and contamination estimation for PAEs in street dust in our study may be over simplified and may not cover all the risks that can occur to human health. Risk to PAE exposure from street dust is high and contamination can occur through different or even combined routes of exposure to these ubiquitous pollutants.

\section{Conclusions}

PAEs are ubiquitously present in street dust of Kaohsiung City. Of the six PAEs studied, DEHP was the most abundant. DEHP levels were found to be from six to seven hundred times higher than DnBP, the second most dominant congener. Commercial zones (night markets) had substantially higher PAE levels compared to industrial and residential areas, suggesting a higher risk to local populations and visitors or tourists. Our study showed that the higher the intensity of anthropogenic activities, the higher the PAE contents in street dust. Adults seemed to be more exposed through skin penetration while children from ingestion. Although we found DIs in street dust to be within acceptable levels, prevention of PAE contamination should still be considered important especially in commercial areas. Night markets make up an integral part of Taiwanese/Asian culture and exposure to PAEs in street dust in these areas is almost unavoidable. Our work can serve as a reference study for further monitoring and pollution prevention endeavors.

\section{Acknowledgements}

The authors acknowledge the enthusiastic assistance of the Center of Environmental Analysis Services (CEAS) and National Kaohsiung University of Science and Technology (NKUST) laboratory staff who have provided us with considerable technical and analytical support. 


\section{References}

Ait Bamai, Y, Araki, A, Kawai, T, Tsuboi, T, Saito, I, Yoshioka, E, Kanazawa, A, Tajima, S, Shi, C, Tamakoshi, A and Kishi, R 2014, 'Associations of phthalate concentrations in floor dust and multi-surface dust with the interior materials in Japanese dwellings', Science of The Total Environment, vol. 468-469, pp. 147-157.

Albar, HMSA, Ali, N, Shahzad, K, Ismail, IMI, Rashid, MI, Wang, W, Ali, LN and Eqani, SAMAS 2017, 'Phthalate esters in settled dust of different indoor microenvironments; source of non-dietary human exposure', Microchemical Journal, vol. 132, pp. 227-232.

Bornehag, C-G, Lundgren, B, Weschler, CJ, Sigsgaard, T, Hagerhed-Engman, L and Sundell, J 2005, 'Phthalates in Indoor Dust and Their Association with Building Characteristics', Environmental Health Perspectives, vol. 113, no. 10 , pp. $1399-1404$.

Caliendo, H 2015. Taiwan's Growing Recycling Market. Plastics Technology. Cincinnati, USA: Gardner Business Media (online).

Chen, CC, Wang, SL, Wu, MT, Wang, YH, Huang, PC, Chen, BH, Sun, CW, Ho, CK, Shih, YC, Shiu, MN, Pan, WH, Chen, ML, Lee, CC and Hsiung, CA 2016, 'Exposure Estimation for Risk Assessment of the Phthalate Incident in Taiwan', Plos One, vol. 11, no. 3, p. e0151070.

Chen, SC, You, ZS and Chang, IY 2014, 'Probabilistic Risk Assessment of Consumer Exposure to Particle-Bound PAHs at a Taiwanese Night Market', International Journal of Environmental Research, vol. 8, no. 3, pp. 643-652.

Chia-Hong, L-L 2013, 'The interaction between the port and Kaohsiung city: Economy, institution and power', City, Culture and Society, vol. 4, no. 1, pp. 21-35.

Guo, Y, Wang, L and Kannan, K 2014, 'Phthalates and Parabens in Personal Care Products From China: Concentrations and Human Exposure', Archives of Environmental Contamination and Toxicology, vol. 66, no. 1 , pp. 113-119.

Hwang, H-M, Park, E-K, Young, TM and Hammock, BD 2008, 'Occurrence of endocrine-disrupting chemicals in indoor dust', Science of the Total Environment, vol. 404, no. 1, pp. 26-35.

Iwegbue, CMA and Obi, G 2016, 'Distribution, sources, and health risk assessment of polycyclic aromatic hydrocarbons in dust from urban environment in the Niger Delta, Nigeria', Human and Ecological Risk Assessment: An International Journal, vol. 22, no. 3, pp. 623-638. 
Jeon, S, Kim, K-T and Choi, K 2016, 'Migration of DEHP and DINP into dust from PVC flooring products at different surface temperature', Science of The Total Environment, vol. 547, pp. 441-446.

Kaewlaoyoong, A, Vu, CT, Lin, C, Liao, CS and Chen, J-R 2018, 'Occurrence of phthalate esters around the major plastic industrial area in southern Taiwan', Environmental Earth Sciences, vol. 77, no. 12, p. 457.

Kang, Y, Man, YB, Cheung, KC and Wong, MH 2012, 'Risk assessment of human exposure to bioaccessible phthalate esters via indoor dust around the Pearl River Delta', Environ Sci Technol, vol. 46, no. 15, pp. 8422-8430.

Kavlock, R, Boekelheide, K, Chapin, R, Cunningham, M, Faustman, E, Foster, P, Golub, M, Henderson, R, Hinberg, I, Little, R, Seed, J, Shea, K, Tabacova, S, Tyl, R, Williams, P and Zacharewski, T 2002, 'NTP Center for the Evaluation of Risks to Human Reproduction: phthalates expert panel report on the reproductive and developmental toxicity of di(2-ethylhexyl) phthalate', Reproductive Toxicology, vol. 16, no. 5, pp. 529-653.

Kluwe, WM 1986, 'Carcinogenic potential of phthalic acid esters and related compounds: structure-activity relationships', Environmental Health Perspectives, vol. 65, pp. 271-278.

Kozumbo, WJ, Kroll, R and Rubin, RJ 1982, 'Assessment of the mutagenicity of phthalate esters', Environmental Health Perspectives, vol. 45, pp. 103-109.

Lan, Q, Cui, KY, Zeng, F, Zhu, F, Liu, H, Chen, HL, Ma, YQ, Wen, JX, Luan, TG, Sun, GQ and Zeng, ZX 2012, 'Characteristics and assessment of phthalate esters in urban dusts in Guangzhou city, China', Environmental Monitoring and Assessment, vol. 184, no. 8, pp. 4921-4929.

Larsson, K, Lindh, CH, Jönsson, BAG, Giovanoulis, G, Bibi, M, Bottai, M, Bergström, A and Berglund, M 2017, 'Phthalates, non-phthalate plasticizers and bisphenols in Swedish preschool dust in relation to children's exposure', Environment International, vol. 102, pp. 114-124.

Lee, S-T, Vu, CT, Lin, C and Chen, KS 2018, 'High occurrence of BTEX around major industrial plants in Kaohsiung, Taiwan', Environmental Forensics, vol. 19, no. 3.

Liao, G 2017. Shilin night market food court to ban melamine, disposable utensils. Taiwan News. Taipei, Taiwan: Taiwan News.

Lin, C, Lee, CJ, Mao, WM and Nadim, F 2009, 'Identifying the potential sources of di-(2-ethylhexyl) phthalate contamination in the sediment of the Houjing River in southern Taiwan', Journal of Hazardous Materials, vol. 161, no. 1, pp. 270-275. 
Lin, C, Nguyen, KA, Vu, CT, Senoro, D and Villanueva, MC 2017a, 'Contamination levels and potential sources of organic pollution in an Asian river', Water Science and Technology, vol. 76, no. 9, pp. 2434-2444.

Lin, C, Nguyen, KA, Vu, CT, Senoro, D and Villanueva, MC 2017b, 'Contamination levels and potential sources of organic pollution in an Asian river', Water Science and Technology.

Niu, LL, Xu, Y, Xu, C, Yun, LX and Liu, WP 2014, 'Status of phthalate esters contamination in agricultural soils across China and associated health risks', Environmental Pollution, vol. 195, pp. 16-23.

Orecchio, S, Indelicato, R and Barreca, S 2013, 'The distribution of phthalate esters in indoor dust of Palermo (Italy)', Environmental Geochemistry and Health, vol. 35, no. 5, pp. 613-624.

Pei, XQ, Song, M, Guo, M, Mo, FF and Shen, XY 2013, 'Concentration and risk assessment of phthalates present in indoor air from newly decorated apartments', Atmospheric Environment, vol. 68, pp. 17-23.

Rane, S 2011, 'Street vended food in developing World: Hazard analyses', Indian Journal of Microbiology, vol. 51, no. 1 , pp. 100-106.

Rudel, RA, Gray, JM, Engel, CL, Rawsthorne, TW, Dodson, RE, Ackerman, JM, Rizzo, J, Nudelman, JL and Brody, JG 2011, 'Food Packaging and Bisphenol A and Bis(2-Ethyhexyl) Phthalate Exposure: Findings from a Dietary Intervention', Environmental Health Perspectives, vol. 119, no. 7, pp. 914-920.

Skrbic, BD, Ji, YQ, Durisic-Mladenovic, N and Zhao, J 2016, 'Occurence of the phthalate esters in soil and street dust samples from the Novi Sad city area, Serbia, and the influence on the children's and adults' exposure', Journal of Hazardous Materials, vol. 312, pp. 272-279.

Subedi, B, Sullivan, KD and Dhungana, B 2017, 'Phthalate and non-phthalate plasticizers in indoor dust from childcare facilities, salons, and homes across the USA', Environmental Pollution, vol. 230, pp. 701-708.

Sun, YM, Wang, ST and Huang, KW 2012, 'Hygiene knowledge and practices of night market food vendors in Tainan City, Taiwan', Food Control, vol. 23, no. 1, pp. 159-164.

Tran, TM, Minh, TB, Kumosani, TA and Kannan, K 2016, 'Occurrence of phthalate diesters (phthalates), phydroxybenzoic acid esters (parabens), bisphenol A diglycidyl ether (BADGE) and their derivatives in indoor dust from Vietnam: Implications for exposure', Chemosphere, vol. 144, pp. 1553-1559.

USEPA 2013, 'Mid Atlantic Risk Assessment. Regional Screening Level (RSL) Summary Table.', United States Environmental Protection Agency, Washington DC, USA. https://www.epa.gov/risk/regional-screeninglevels-rsls-generic-tables-may-2016. Accessed 16 Mar 2017 
Vu, CT, Lin, C, Shern, C-C, Yeh, G, Le, VG and Tran, HT 2017a, 'Contamination, ecological risk and source apportionment of heavy metals in sediments and water of a contaminated river in Taiwan', Ecological Indicators, vol. 82, pp. 32-42.

Vu, CT, Lin, C, Yeh, G and Villanueva, MC 2017b, 'Bioaccumulation and potential sources of heavy metal contamination in fish species in Taiwan: assessment and possible human health implications', Environmental Science and Pollution Research, vol. 24, no. 23, pp. 19422-19434.

Wu, MT, Wu, CF, Chen, BH, Chen, EK, Chen, YL, Shiea, J, Lee, WT, Chao, MC and Wu, JR 2013, 'Intake of Phthalate-Tainted Foods Alters Thyroid Functions in Taiwanese Children', Plos One, vol. 8, no. 1, p. e55005.

Wu, MT, Wu, CF, Wu, JR, Chen, BH, Chen, EK, Chao, MC, Liu, CK and Ho, CK 2012, 'The public health threat of phthalate-tainted foodstuffs in Taiwan: The policies the government implemented and the lessons we learned', Environment International, vol. 44, pp. 75-79.

Wu, W, Hu, J, Wang, JQ, Chen, XR, Yao, N, Tao, J and Zhou, YK 2015, 'Analysis of phthalate esters in soils near an electronics manufacturing facility and from a non-industrialized area by gas purge microsyringe extraction and gas chromatography', Science of the Total Environment, vol. 508, pp. 445-451.

Yang, GCC, Yen, C-H and Wang, C-L 2014, 'Monitoring and removal of residual phthalate esters and pharmaceuticals in the drinking water of Kaohsiung City, Taiwan', Journal of Hazardous Materials, vol. 277, pp. 53-61.

Zeng, F, Cui, KY, Xie, ZY, Liu, M, Li, YJ, Lin, YJ, Zeng, ZX and Li, FB 2008a, 'Occurrence of phthalate esters in water and sediment of urban lakes in a subtropical city, Guangzhou, South China', Environment International, vol. 34, no. 3, pp. 372-380.

Zeng, F, Cui, KY, Xie, ZY, Wu, LN, Liu, M, Sun, GQ, Lin, YJ, Luo, DL and Zeng, ZX 2008b, 'Phthalate esters (PAEs): Emerging organic contaminants in agricultural soils in peri-urban areas around Guangzhou, China', Environmental Pollution, vol. 156, no. 2, pp. 425-434.

Zhang, Q, Lu, XM, Zhang, XL, Sun, YG, Zhu, DM, Wang, BL, Zhao, RZ and Zhang, ZD 2013, 'Levels of phthalate esters in settled house dust from urban dwellings with young children in Nanjing, China', Atmospheric Environment, vol. 69, pp. 258-264.

Zhang, Y, Liang, Q, Gao, R, Hou, H, Tan, W, He, X, Zhang, H, Yu, M, Ma, L, Xi, B and Wang, X 2015, 
'Contamination of phthalate esters (PAEs) in typical wastewater-irrigated agricultural soils in Hebei, North China', PLOS One, vol. 10, no. 9, p. e0137998.

Zhao, P, Yu, KP and Lin, CC 2011, 'Risk assessment of inhalation exposure to polycyclic aromatic hydrocarbons in Taiwanese workers at night markets', International Archives of Occupational and Environmental Health, vol. 84 , no. 3, pp. 231-237.

Zheng, L, Tang, Q, Fan, J, Huang, X, Jiang, C and Cheng, H 2015, 'Distribution and health risk assessment of mercury in urban street dust from coal energy dominant Huainan City, China', Environmental Science and Pollution Research, vol. 22, no. 12, pp. 9316-9322. 


\section{List of figure captions}

Figure 1 Sampling sites for street dust collected in Kaohsiung City, Taiwan (Source: Google maps, 2018).

Figure 2 Sampling stations considered in the Houjing night market (Nanzih District), Kaohsiung

City (Source: Google maps, 2018).

Figure 3 Levels of total PAEs in street dust $\left(\mathrm{mg} \mathrm{kg}^{-1}\right)$ in the central (mean \pm SD) and adjacent sampling sites of the Houjing night market (Nanzih District). The central area is the average value of PAEs observed in $\mathrm{H} 1$ to $\mathrm{H} 4$.

\section{List of table captions}

Table 1 Concentration levels of street dust PAEs $\left(\mathrm{mg} \mathrm{kg}^{-1}\right)$ in different areas of Kaohsiung City (ND: not detected).

Table 2 Comparison of average PAE concentrations $\left(\mathrm{mg} \mathrm{kg}^{-1}\right)$ in street dust in different geographical areas. In bold are values of 'high' concentrations for a specific compound. Values are shown as average range (mean \pm standard deviation or mean ${ }^{\mathrm{a}}$ ). ND: not detected. ............. 25 Table 3 Descriptive statistics of measured PAE concentrations $\left(\mathrm{mg} \mathrm{kg}^{-1}\right)$ based on the intensity of human activities in sampling sites of residential areas of Kaohsiung City, Taiwan (ND: not detected). 25

Table 4 Daily intake (DI, $\mu \mathrm{g} \mathrm{kg}^{-1}$ bw day ${ }^{-1}$ ) estimation of exposure in adults and children to street dust PAEs via ingestion and dermal contact. 


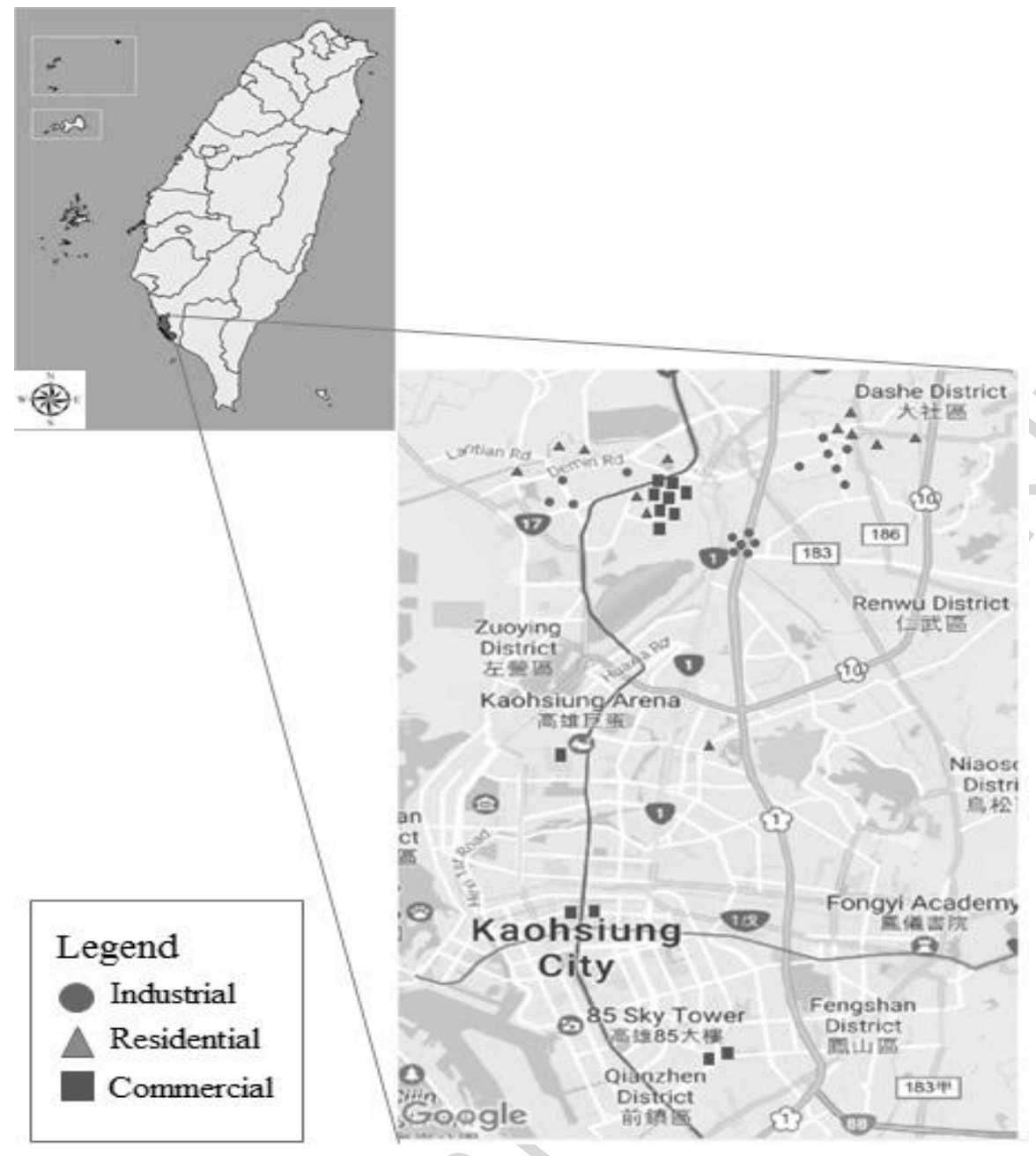

Figure 1 Sampling sites for street dust collected in Kaohsiung City, Taiwan (Source: Google maps, 2018). 


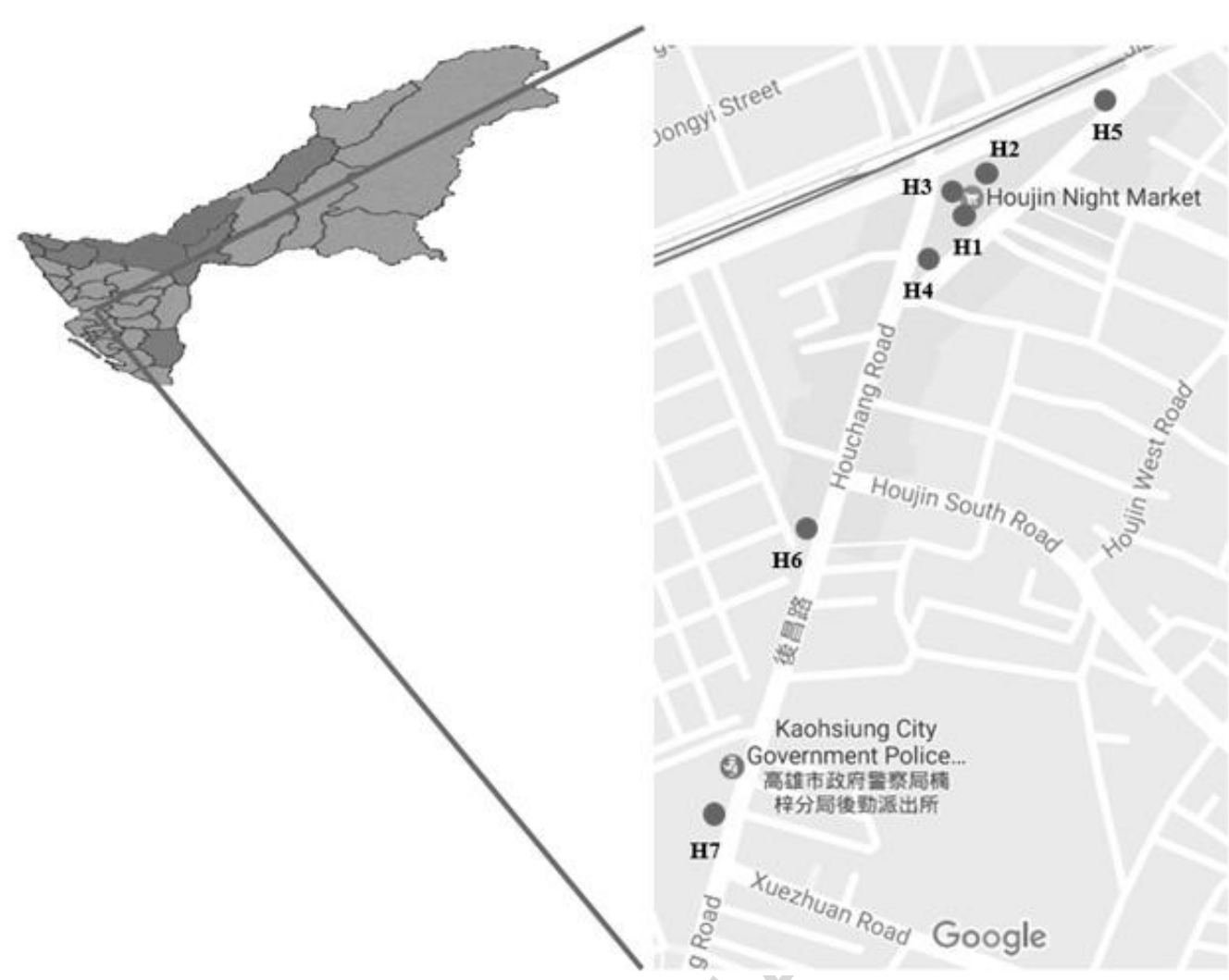

Figure 2 Sampling stations considered in the Houjing night market (Nanzih District), Kaohsiung City (Source: Google maps, 2018). 


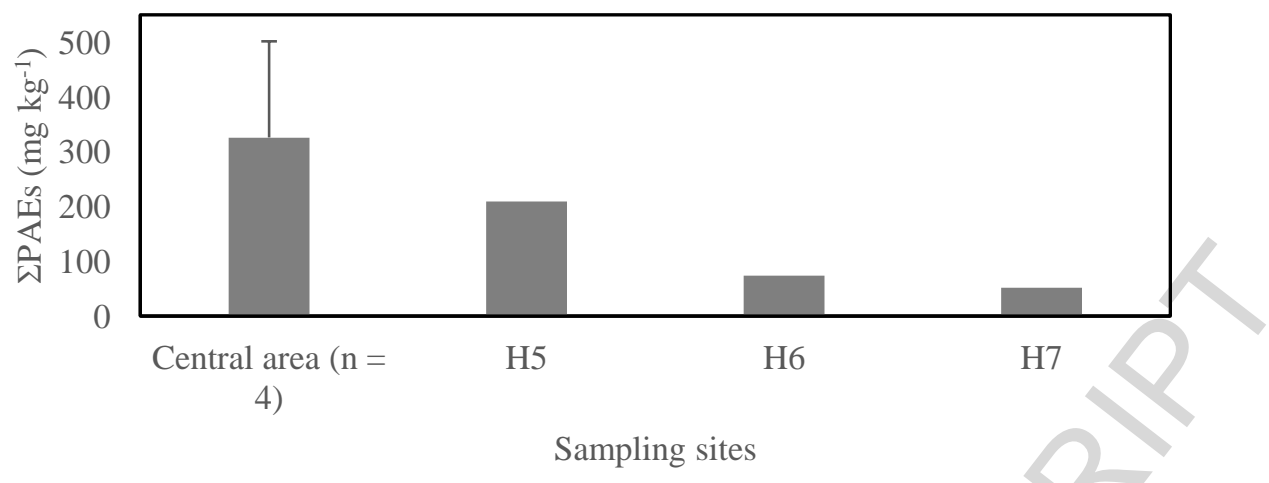

Figure 3 Levels of total PAEs in street dust $\left(\mathrm{mg} \mathrm{kg}^{-1}\right)$ in the central (mean \pm SD) and adjacent sampling sites of the Houjing night market (Nanzih District). The central area is the average value of PAEs observed in $\mathrm{H} 1$ to $\mathrm{H} 4$. 
Table 1 Concentration levels of street dust PAEs $\left(\mathrm{mg} \mathrm{kg}^{-1}\right)$ in different areas of Kaohsiung City (ND: not detected).

\begin{tabular}{|c|c|c|c|c|c|c|c|c|c|c|c|c|c|c|c|}
\hline \multirow{3}{*}{$\begin{array}{l}\text { PAEs } \\
\text { DEHP }\end{array}$} & \multicolumn{6}{|c|}{ Industrial $(\mathrm{n}=17)$} & \multicolumn{5}{|c|}{ Residential $(n=22)$} & \multicolumn{4}{|c|}{ Commercial $(n=13)$} \\
\hline & \multicolumn{3}{|c|}{ Range } & \multirow{2}{*}{$\begin{array}{r}\text { Mean } \\
77\end{array}$} & \multirow{2}{*}{$\begin{array}{l}\text { SD } \\
220.5\end{array}$} & \multirow{2}{*}{$\begin{array}{l}\text { Median } \\
16\end{array}$} & \multicolumn{2}{|l|}{ Range } & \multirow{2}{*}{$\begin{array}{r}\text { Mean } \\
55\end{array}$} & \multirow{2}{*}{$\begin{array}{l} \pm \mathrm{SD} \\
\pm 75\end{array}$} & \multirow{2}{*}{$\begin{array}{l}\text { Median } \\
28\end{array}$} & \multirow{2}{*}{$\begin{array}{r}\frac{\text { Range }}{97-699}\end{array}$} & \multirow{2}{*}{$\begin{array}{r}\text { Mean } \\
422\end{array}$} & \multirow{2}{*}{$\begin{array}{l} \pm \mathrm{SD} \\
\pm 176\end{array}$} & \multirow{2}{*}{$\begin{array}{l}\text { Median } \\
438\end{array}$} \\
\hline & 4 & - & 956 & & & & 6 & -363 & & & & & & & \\
\hline $\mathrm{D} n \mathrm{BP}$ & ND & - & 13 & 8 & \pm 4 & 10 & 4 & -22 & 9 & \pm 4 & 9 & ND - 29 & 6 & \pm 9 & 4 \\
\hline $\mathrm{D} n \mathrm{OP}$ & 1 & - & 18 & 4 & \pm 5 & 3 & ND & -7 & 3 & \pm 1 & 3 & 2 & 5 & \pm 3 & 5 \\
\hline $\mathrm{BBP}$ & & ND & & 1 & \pm 1 & 2 & ND & -2 & & \pm 1 & 2 & & ND & \pm 1 & ND \\
\hline DEP & & ND & & & ND & ND & ND & -1 & & ND & ND & ND - 1 & & ND & ND \\
\hline DMP & & ND & & & ND & ND & & ND & & ND & ND & ND - 1 & & ND & ND \\
\hline$\Sigma$ PAEs & 5 & - & 989 & 91 & \pm 230 & 30 & 10 & - 395 & 68 & \pm 81 & 41 & $99-740$ & 435 & \pm 188 & 448 \\
\hline
\end{tabular}


Table 2 Comparison of average PAE concentrations $\left(\mathrm{mg} \mathrm{kg}^{-1}\right)$ in street dust in different geographical areas. In bold are values of 'high' concentrations for a specific compound. Values are shown as average range (mean \pm standard deviation or mean ${ }^{\mathrm{a}}$ ). ND: not detected.

\begin{tabular}{|c|c|c|c|c|c|c|c|}
\hline Geographical areas & DMP & DEP & DnBP & BBP & DEHP & DnOP & References \\
\hline \multirow[t]{2}{*}{ Kaohsiung City, Taiwan } & $\mathrm{ND}-\mathbf{0 . 8}$ & $\mathrm{ND}-\mathbf{0 . 5}$ & ND - 29.1 & $\mathrm{ND}-\mathbf{2 . 1}$ & $4.4-955.6$ & ND - 17.7 & This study \\
\hline & $\mathbf{0 . 1} \pm 0.2$ & $\mathbf{0 . 2} \pm 0.2$ & $8.3 \pm 5.5$ & $0.9 \pm 0.8$ & $153.9 \pm 224$ & $4 \pm 3.2$ & \\
\hline \multirow[t]{2}{*}{ Guangzhou, China } & $0.038-0.122$ & $0.027-0.117$ & $7.77-\mathbf{5 9 . 5}$ & $1.14-\mathbf{1 0 . 7}$ & $125-779$ & $0.914-\mathbf{3 . 7 3}$ & (Lan et al. 2012) \\
\hline & $0.079 \pm 0.031$ & $0.064 \pm 0.029$ & $27.5 \pm 15.7$ & $\mathbf{2 . 2 3} \pm 2.39$ & $344 \pm 172$ & $\mathbf{2 . 2 6} \pm 0.822$ & \\
\hline \multirow[t]{2}{*}{ Novi Sad, Serbia } & $0.004-0.021$ & $0.003-0.017$ & $0.02-0.213$ & $0.0002-0.351$ & $0.128-4.82$ & $0.001-0.035$ & (Skrbic et al. 2016) \\
\hline & $0.009^{\mathrm{a}}$ & 0.006 & 0.071 & 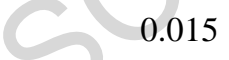 & 1.22 & 0.01 & \\
\hline Nanjing, China & $0.02 \pm 0.005$ & $0.1 \pm 0.009$ & $2.3 \pm 0.00$ & $0.1 \pm 0.009$ & $11.5 \pm 0.02$ & $0.03 \pm 0.008$ & (Zhang et al. 2013) \\
\hline
\end{tabular}

Table 3 Descriptive statistics of measured PAE concentrations $\left(\mathrm{mg} \mathrm{kg}^{-1}\right)$ based on the intensity of human activities in sampling sites of residential areas of Kaohsiung City, Taiwan (ND: not detected).

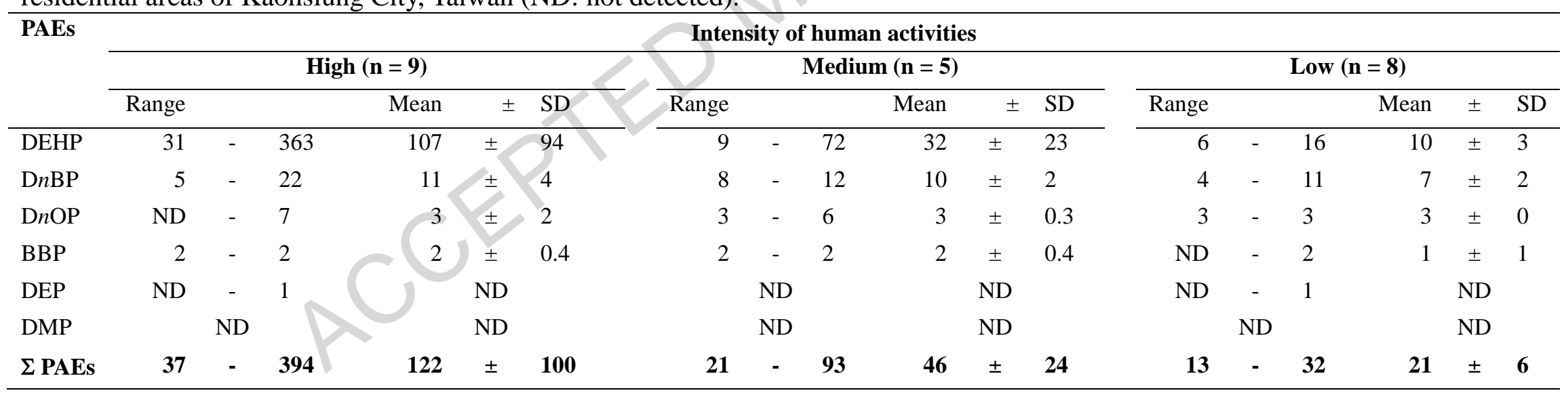


Table 4 Daily intake (DI, $\mu \mathrm{g} \mathrm{kg}^{-1}$ bw day ${ }^{-1}$ ) estimation of exposure in adults and children to street dust PAEs via ingestion and dermal contact.

\begin{tabular}{|c|c|c|c|c|c|c|c|c|c|}
\hline & $\begin{array}{l}\text { Exposure } \\
\text { pathways }\end{array}$ & & DEHP & DnBP & DnOP & BBP & DEP & DMP & $\Sigma$ PAEs \\
\hline \multirow[t]{6}{*}{ Adults } & Ingestion & Mean & 4.40E-02 & $2.36 \mathrm{E}-03$ & $1.13 \mathrm{E}-03$ & $2.69 \mathrm{E}-04$ & $4.50 \mathrm{E}-05$ & $2.93 \mathrm{E}-05$ & $4.78 \mathrm{E}-02$ \\
\hline & & $\pm \mathrm{SD}$ & $\pm 6.40 \mathrm{E}-02$ & $\pm 1.57 \mathrm{E}-03$ & \pm 8.99E-04 & $\pm 2.27 \mathrm{E}-04$ & $\pm 4.33 \mathrm{E}-05$ & $\pm 4.44 \mathrm{E}-05$ & $\pm 6.68 \mathrm{E}-02$ \\
\hline & & Median & $9.95 \mathrm{E}-03$ & $2.43 \mathrm{E}-03$ & 7.87E-04 & 4.30E-04 & $2.43 \mathrm{E}-05$ & $1.03 \mathrm{E}-05$ & $1.36 \mathrm{E}-02$ \\
\hline & Dermal & Mean & $8.77 \mathrm{E}-02$ & $4.71 \mathrm{E}-03$ & $2.26 \mathrm{E}-03$ & $5.36 \mathrm{E}-04$ & 8.99E-05 & $5.84 \mathrm{E}-05$ & $9.54 \mathrm{E}-02$ \\
\hline & & $\pm \mathrm{SD}$ & $\pm 1.28 \mathrm{E}-01$ & $\pm 3.13 \mathrm{E}-03$ & $\pm 1.79 \mathrm{E}-03$ & $\pm 4.53 \mathrm{E}-04$ & $\pm 8.63 \mathrm{E}-05$ & $\pm 8.85 \mathrm{E}-05$ & $\pm 1.33 \mathrm{E}-01$ \\
\hline & & Median & $1.99 \mathrm{E}-02$ & $4.84 \mathrm{E}-03$ & $1.57 \mathrm{E}-03$ & $8.58 \mathrm{E}-04$ & $4.85 \mathrm{E}-05$ & $2.05 \mathrm{E}-05$ & $2.72 \mathrm{E}-02$ \\
\hline \multirow[t]{6}{*}{ Children } & Ingestion & Mean & $5.13 \mathrm{E}-01$ & $2.76 \mathrm{E}-02$ & $1.32 \mathrm{E}-02$ & $3.13 \mathrm{E}-03$ & $5.26 \mathrm{E}-04$ & $3.42 \mathrm{E}-04$ & $5.58 \mathrm{E}-01$ \\
\hline & & $\pm \mathrm{SD}$ & $\pm 7.47 \mathrm{E}-01$ & $\pm 1.83 \mathrm{E}-02$ & $\pm 1.05 \mathrm{E}-02$ & $\pm 2.65 \mathrm{E}-03$ & $\pm 5.05 \mathrm{E}-04$ & $\pm 5.18 \mathrm{E}-04$ & $\pm 7.79 \mathrm{E}-01$ \\
\hline & & Median & $1.16 \mathrm{E}-01$ & $2.83 \mathrm{E}-02$ & $9.18 \mathrm{E}-03$ & $5.02 \mathrm{E}-03$ & $2.83 \mathrm{E}-04$ & $1.20 \mathrm{E}-04$ & $1.59 \mathrm{E}-01$ \\
\hline & Dermal & Mean & $5.75 \mathrm{E}-01$ & $3.09 \mathrm{E}-02$ & $1.48 \mathrm{E}-02$ & $3.51 \mathrm{E}-03$ & $5.89 \mathrm{E}-04$ & $3.83 \mathrm{E}-04$ & $6.25 \mathrm{E}-01$ \\
\hline & & $\pm \mathrm{SD}$ & $\pm 8.36 \mathrm{E}-01$ & $\pm 2.05 \mathrm{E}-02$ & $\pm 1.18 \mathrm{E}-02$ & $\pm 2.96 \mathrm{E}-03$ & $\pm 5.65 \mathrm{E}-04$ & $\pm 5.80 \mathrm{E}-04$ & $\pm 8.73 \mathrm{E}-01$ \\
\hline & & Median & $1.30 \mathrm{E}-01$ & 17E-02 & $1.03 \mathrm{E}-02$ & $5.62 \mathrm{E}-03$ & $3.17 \mathrm{E}-04$ & $1.34 \mathrm{E}-04$ & $1.78 \mathrm{E}-01$ \\
\hline
\end{tabular}




\section{Graphical abstract}
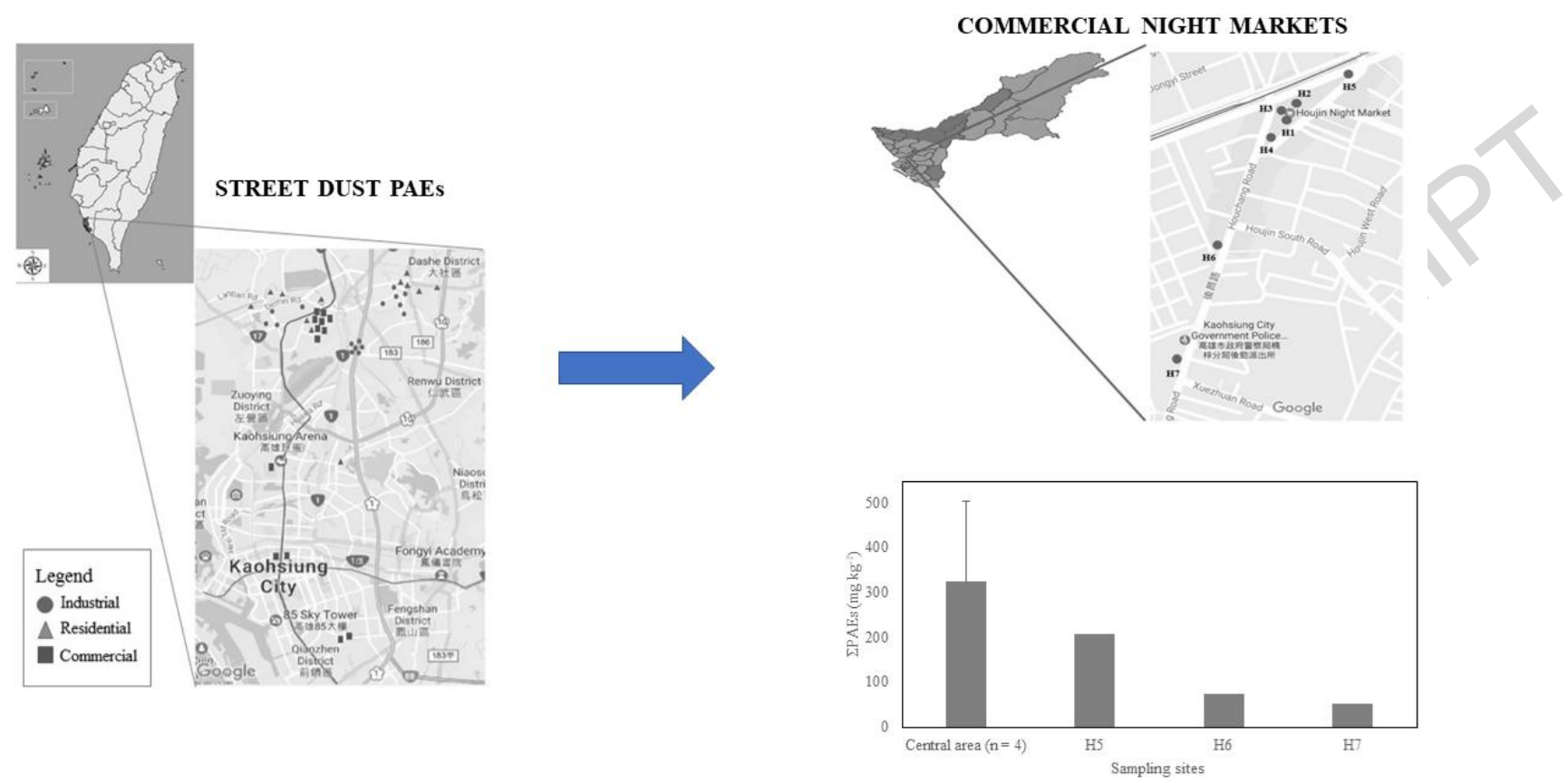